\title{
Comparative analysis of maternal and fetal outcome in meconium stained amniotic fluid and clear liquor in primigravida
}

\author{
Deepali S. Kapote*, Apeksha M. Mohite, Anam Syed
}

Department of Obstetrics and Gynecology, LTMMC and LTMGH Mumbai, Maharashtra, India

Received: 10 October 2019

Accepted: 10 January 2020

\section{*Correspondence:}

Dr. Deepali S. Kapote,

E-mail: drdeepalikapote@gmail.com

Copyright: (C) the author(s), publisher and licensee Medip Academy. This is an open-access article distributed under the terms of the Creative Commons Attribution Non-Commercial License, which permits unrestricted non-commercial use, distribution, and reproduction in any medium, provided the original work is properly cited.

\begin{abstract}
Background: The present study was undertaken to evaluate the significance of MSAF and its fetal outcome in parturients.

Methods: A total of 121 pregnant women who had completed more than 37 weeks of gestation with live singleton pregnancy, spontaneous onset of labor and at term with adequate pelvis were included in the study. All (121) low risk primigravida with MSAF were studied to identify maternal and fetal outcome and compared with equal number of cases with clear amniotic fluid. Meconium stained cases were clinically classified into two groups- thin (54 cases) and thick (67 cases). MSAF on spontaneous or artificial rupture of membranes were monitored with fetal heart rate abnormality, 1- and 5-minutes Apgar score, NICU admissions and neonatal complications as outcome variables.

Results: Overall incidence of meconium staining of AF during labour was $7.71 \%$. The common fetal heart rate abnormalities i.e. bradycardia was seen in 36\% in MSG. Apgar score of less than 7 was observed in MSG at 5 minutes in 5\% of cases, in thick group. Major neonatal complication was birth asphyxia in MSG (18.18\%) that was more in thick MSG (14.87\%). MAS were observed in 6 cases in thick and 4 cases in thin meconium stained cases. NICU care was required in $18 \%$ cases in MSG and in control group it was required in $7 \%$ cases. Neonatal morbidity was more in newborn with thick meconium group (52\%) compared to thin meconium group (20\%).

Conclusions: The present study confirmed that meconium staining of amniotic fluid adversely influences the fetal outcome.
\end{abstract}

Keywords: Apgar score, Birth asphyxia, Meconium aspiration syndrome, Meconium stained amniotic fluid, Meconium stained group, Primigravidas

\section{INTRODUCTION}

A substance which accumulates in the fetal bowel during the intra uterine life is called meconium. Meconium in greek language means substance resembling poppy juice and contains GIT secretions, bile juice, cellar debris, amniotic fluid swallowed vernix caseosa, lanugo, blood. ${ }^{1}$ It is a green, viscous liquid that first appears in fetal ileum from 10 weeks gestation and incidence of intrauterine passage of meconium increases with the gestational age. ${ }^{2}$ There are three theories to explain fetal passage of meconium, one is in response to hypoxia or asphyxia, meconium is passed and signals fetal compromise. $^{3}$ Secondly it represents normal GIT maturation under neural control. Third it is associated with vagal stimulation from common but transient umbilical cord entrapment and resultant increased peristalsis and results in meconium stained liquor with FHR variation in $10-15 \% .^{4}$

Meconium aspiration syndrome (MAS) is defined as a respiratory distress that develops shortly after birth, with radiographic evidence of aspiration pneumonitis and presence of meconium stained amniotic fluid. ${ }^{5}$ Meconium 
stained infants are considered 100 times more likely to develop MAS compared with infants born through clear amniotic fluid, and more than $4 \%$ of MAS infants died accounting for $2 \%$ of all perinatal deaths. ${ }^{6}$ The Amniotic fluid index, as measured by the four quadrant ultrasonic technique was added to antepartum testing to better identify fetuses at higher risk of poor perinatal outcome. ${ }^{7,8}$ Oligohydramnios or decreased amniotic fluid, has since been correlated with increased risk of meconium passage, abnormal fetal heart rate patterns, and lower Apgar scores in multiple studies. ${ }^{9}$

\section{METHODS}

After obtaining institutional ethical committee approval and patients' written informed consent, present prospective observational study was conducted in 121 cases with equal number of controls in the department of obstetrics and gynaecology, tertiary care hospital of Mumbai, over a period of August 2018-August 2019. All low risk primigravida who were more than 37 weeks of gestation with live singleton pregnancy, and cephalic presentation with spontaneous onset of labor, at term with adequate pelvis, in whom presence of meconium in amniotic fluid on spontaneous rupture of membranes (SRM) or artificial rupture of membranes (ARM) were included in the study. Exclusion criteria - included pregnancies less than 37 weeks of gestational age $/>42$ weeks, pregnancy with any fetal malformations, malpresentations, antepartum haemorrhage/PROM, multiple pregnancy, intrauterine fetal death, intrauterine growth retardation, maternal medical diseases like preeclampsia, diabetes, cardiac or renal disease.

Cases were those with meconium stained amniotic fluid and a control group with clear amniotic fluid. Meconium stained cases were clinically classified into two groups according to type of staining-thin (54 cases- lightly stained amniotic fluid, yellow or greenish in colour) and thick (67 cases- darkly stained amniotic fluid, dark green or black usually thick and tenacious). All the information regarding cases and controls were noted in a predesigned printed proforma vide Annexure. Amniotic fluid index (AFI) in both groups done within 7 days prior to delivery was noted. General and obstetrical examination of mother during labour was done. The labour was monitored electronically, the mode of delivery, Apgar scores at one and five minutes, birth weight, sex, resuscitation of baby, neonatal intensive care (NICU) admissions, birth asphyxia, meconium aspiration syndrome (MAS), early neonatal deaths were recorded. Use of any medications like oxytocin, sedatives, analgesics or any transfusion was also noted. Clinical fetal monitoring i.e. fetal heart rate was also noted at the time of collecting the MSAF. All babies of both group followed up to 1 st week of neonatal life.

In present study bradycardia was considered when fetal heart rate below $100 \mathrm{bpm}$. and tachycardia when fetal heart rate above $160 \mathrm{bpm}$. Fetal distress included FHR abnormalities (bradycardia, tachycardia, significant variable deceleration, loss of beat to beat variability, fetal arrythmias), decreased or absent fetal movements and Non-reactive NST. Babies were considered nonasphyxiated and in good condition when Apgar score were 7 or more. Babies were considered moderately asphyxiated when score was 4 to 6 and were considered grossly asphyxiated when score was below 4 .

\section{Statistical analysis}

The statistical analysis was done using SPSS Software Ver. 17. All the qualitative data were presented as frequency and percentages and were compared using Fisher ${ }^{\text {ee }}$ s test or Chi-square test. P- Value of $<0.05$ was considered as significant.

\section{RESULTS}

During the study period of one year, the total numbers of deliveries were 8965 , of which 121 cases had meconium staining of amniotic fluid, giving the incidence of $7.71 \%$. Among these 121 cases, 67 cases had thick meconium and 54 cases had thin meconium. In study group maximum numbers of cases $(54.54 \%)$ were in the age group of 21- 25 years and mean age group was 23.6 years. In the control group also maximum number of cases $(57.85 \%)$, were in the same age group and mean age was 22.98 years. Approximately $62.80 \%$ had gestational ages of 39-40 weeks, was higher in study group as compared to controls (57.02), but difference was not statistically significant. Unbooked cases were more in study group as compare to in control group. Out of unbooked cases of MSG 33\% were of thick meconium stained, (Table 1).

Table 1: Prevalence of MSAF in relation to maternal age, gestational age, booking states.

\begin{tabular}{|lll|}
\hline Parameters & Cases $(\%)$ & Control $(\%)$ \\
\hline Maternal age & & \\
\hline$<20$ years & 23.14 & 25.61 \\
\hline 21-25 years & 54.54 & 57.85 \\
\hline 26-30 years & 18.18 & 16.52 \\
\hline 31-36 years & 4.13 & 00.00 \\
\hline Gestational age & & \\
\hline 37-38 weeks & 37.19 & 42.97 \\
\hline 39-40 weeks & 62.80 & 57.02 \\
\hline Booked & 72.72 & 80.99 \\
\hline Unbooked & 27.27 & 19.00 \\
\hline
\end{tabular}

Normal vaginal deliveries were more in control group than in study group and difference was statistically significant. Incidence of caesarean section was highest in thick group $(59.70 \%)$ compared to $24 \%$ in thin group while incidence was 5 times more in thick group in comparison to control group $(12.39 \%)$, ( $\mathrm{P}<0.01)$. Outlet forceps delivery and vacuum extraction was also more in meconium stained group than control group (Table 2). 
Table 2: Mode of delivery.

\begin{tabular}{|llll|}
\hline \multirow{2}{*}{ Parameters } & Study group & Thick group $(\mathbf{n = 6 7 )}$ & Control group \\
\hline Normal deliveries & Thin group $(\mathbf{n = 5 4 )}$ & $13(19.4 \%)$ & $86(71.07 \%)$ \\
\hline Cesarean section & $22(40.74 \%)$ & $40(59.70 \%)$ & $15(12.39 \%)$ \\
\hline Forceps deliveries & $13(24.07 \%)$ & $13(19.4 \%)$ & $11(9.09 \%)$ \\
\hline Vacuum extraction & $12(22.22 \%)$ & $1(1.49 \%)$ & $9(7.43 \%)$ \\
\hline
\end{tabular}

Table 3: Correlation of low amniotic fluid index with cesarean delivery.

\begin{tabular}{|lllll|}
\hline \multirow{2}{*}{ Amniotic fluid index } & Study group & & & Control group \\
\hline$<5$ & Thin group $(\mathbf{n = 5 4 )}$ & Thick group $(\mathbf{n = 6 7 )}$ & Total & $3(20.00 \%)$ \\
\hline$>5$ & $5(38.46 \%)$ & $16(40.00 \%)$ & $21(39.62 \%)$ & $32(60.37 \%)$ \\
\hline Total & $8(61.53 \%)$ & $24(60.00 \%)$ & $12(80.00 \%)$ \\
\hline
\end{tabular}

Table 4: Correlation of intrapartum fetal heart rate and condition of baby at birth in MSG and control group.

\begin{tabular}{|lllllllll|}
\hline $\begin{array}{l}\text { Fetal } \\
\text { heart rate }\end{array}$ & $\begin{array}{l}\text { Study group } \\
\text { No. of } \\
\text { cases }\end{array}$ & Still birth & $\begin{array}{l}\text { Grossly } \\
\text { asphyxiated }\end{array}$ & $\begin{array}{l}\text { Moderately } \\
\text { asphyxiated }\end{array}$ & $\begin{array}{l}\text { No. of } \\
\text { cases }\end{array}$ & $\begin{array}{l}\text { Still } \\
\text { birth }\end{array}$ & $\begin{array}{l}\text { Grossly } \\
\text { asphyxiated }\end{array}$ & $\begin{array}{l}\text { Moderately } \\
\text { asphyxiated }\end{array}$ \\
\hline$<120 \mathrm{bpm}$ & $44(36 \%)$ & $1(0.82 \%)$ & $3(2.47 \%)$ & $9(7.43 \%)$ & $21(14 \%)$ & 0 & $0(0.00 \%)$ & $2(1.65 \%)$ \\
\hline$>160 \mathrm{bpm}$ & $16(13 \%)$ & $0(0.00 \%)$ & $1(0.82 \%)$ & $1(0.82 \%)$ & $10(2 \%)$ & 0 & $1(0.82 \%)$ & $0(0.00 \%)$ \\
\hline $120-160 \mathrm{bpm}$ & $61(51 \%)$ & $0(0.00 \%)$ & $0(0.00 \%)$ & $8(14.87 \%)$ & $90(84 \%)$ & 0 & $0(0.00 \%)$ & $6(4.95 \%)$ \\
\hline
\end{tabular}

Among 53 cases of caesarean done in MSG, 21 cases had AFI less than 5 compared to 3 cases in control group. The number of meconium staining associated with low amniotic fluid index and cesarean delivery was twice in study group as compared to control group though not statistically significant (Table 3 ).

In meconium stained group male babies were more (56\%) where as in control group it was $52 \%$ as well as mean birth weight was $2.92 \mathrm{kgs}$ in MSG and it was $2.88 \mathrm{kgs}$ in control group, the difference was not statistically significant. Approximately $18.18 \%$ babies in meconium stained group suffered from birth asphyxia (Moderate +
Gross asphyxia) compared to $7.43 \%$ in control group. The commonest associated abnormal fetal heart rate pattern observed in this study was bradycardia (36\%) in MSG. There was 1 still birth in study group. The number of babies in MSG with FHR < 120 bpm was statistically significant as compared to babies in control group. The condition of baby at birth was worse in MSG as compared to control group which was also statistically significant (P-value < 0.01) (Table 4). The number of babies with non-reactive NST was more in thick MSG (51\%) as compared to thin MSG (20\%) and control group $(16 \%)$, which was statistically significant (P-value < $0.01)$.

Table 5: Perinatal outcome.

\begin{tabular}{|lllll|}
\hline Parameters & Study group & & & Total \\
& Thin group & Thick group & Control group \\
\hline Birth asphyxia & $4(3.3 \%)$ & $18(14.87 \%)$ & $22(18.18 \%)$ & - \\
\hline MAS & $4(3.3 \%)$ & $6(4.95 \%)$ & $10(8.25 \%)$ & - \\
\hline Neonatal morbidity & $9(7.43 \%)$ & $22(18.18 \%)$ & $31(25.61 \%)$ & $21(17 \%)$ \\
\hline Still birth & - & $1(0.82 \%)$ & $1(0.82 \%)$ & $1(0.82 \%)$ \\
\hline Early neo-natal death & - & $4(3.30 \%)$ & $4(3.3 \%)$ & - \\
\hline
\end{tabular}

Among the stained cases 4 cases of thick MSG babies were grossly asphyxiated having Apgar score at 1 minute
1-3 and at five-minute score was high in between 4-6. Among MSG 95\% babies had Apgar score at 5 minute 710 in comparison to control group it was $98 \%$. Among 
control group 1 baby was grossly asphyxiated having Apgar score at one minute 1-3 but Apgar score was 4-6 at five minutes. Numbers of asphyxiated babies were 22 in MSG where as in control group it was 9. The Apgar score at one minute in MSG of 1-3 was statistically significant, between thick and thin MSG; and MSG and control group, whereas there was no difference at five-minute Apgar score. Apgar score below 7 was $7.27 \%$ in study group whereas there was no baby having Apgar score below 7 in control group. Apgar score at 5 minutes in cases of LSCS in meconium stained group and control group was not statistically significant. Apgar score of less than 7 was observed in MSG at 5 minutes in 5\% of cases, in thick group (Figure 1).

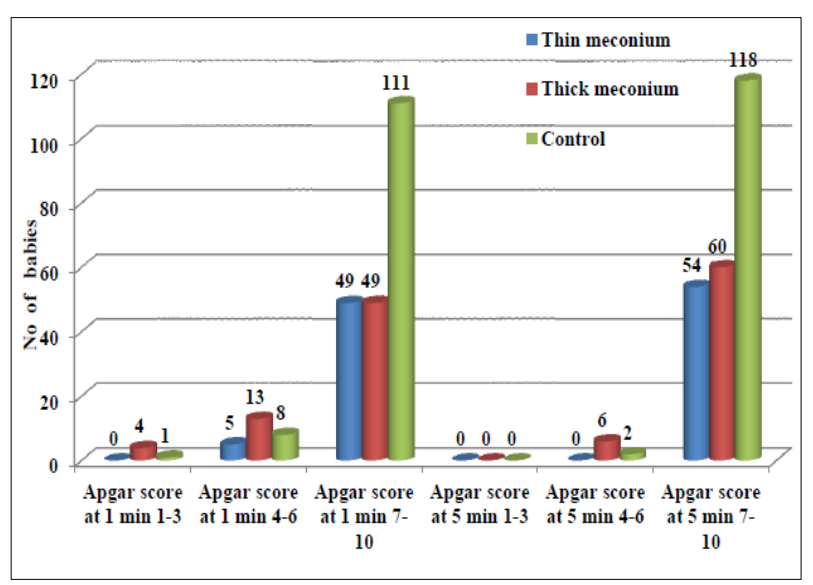

Figure 1: Correlation of 1 minute and 5-minute Apgar score in study group in comparison with control group.

Major neonatal complication was birth asphyxia in MSG that was more in thick MSG. MAS were observed in 6 cases out of 67 thick meconium stained cases and 4 cases out of 54 thin meconium stained cases. NICU care was required in $18 \%$ cases in MSG whereas $7 \%$ cases in control group. $>7$ days NICU stay was required by 9 cases of MSG that was about 8 times more in comparison to control group. Neonatal morbidity was more in newborn with thick meconium group $(52 \%)$ compared to thin meconium stained group (20\%). Early neonatal mortality was $100 \%$ associated with thick MSG. Early neonatal death was 4 in thick MSG and it was due to MAS. Still birth was $0.82 \%$ in MSG whereas nil in control group. Perinatal mortality was $4 \%$ in MSG that was associated with thick MSG and $0.82 \%$ in control group (Table 5).

\section{DISCUSSION}

In present study out of 8965 deliveries, 121 cases of MSAF were studied during the period of 12 months to evaluate the effect of MSAF during labor on fetal outcome; an equal number of cases with clear AF were taken as control. 54 of the 121 cases had thin MSAF and 67 had thick MSAF noted at the time of spontaneous or artificial rupture of membranes. The incidence of MSAF in our study was $7.71 \%$, among the MSAF cases the highest incidence was found in thick MSAF which was comparable to other studies having incidence from 9.8 to $11 \% .^{10-13}$ The mean gestational age was higher $(39.82$ weeks) in study group than control (38.8 weeks) which was similar to that as seen in Rosario $1996 .{ }^{14}$ Meconium staining of amniotic fluid does not appear to be related to amniotic fluid volume in term pregnancies, and its presence increases the risk of cesarean delivery for fetal distress independent of amniotic fluid volume. ${ }^{15} \mathrm{We}$ found significantly higher incidence of risk factors in MSG group that was similar to the study of Kamala et al. ${ }^{16}$ However the incidence of caesarean section was highest in thick meconium group, that was $59.70 \%$ and out of total MSAF cases $48 \%$ delivered by caesarean section whereas in control group it was $12 \%$. In comparison to thin group incidence of caesarean section was near about double in thick group. In the study group overall percentage of caesarean section due to fetal distress indicated by MSAF and abnormal NST. Our result correlates with result of Goud $\mathrm{P}$, Patil et al and Naveen et al, Wong SF reported lower rates of caesarean section in their study, such lower rates of caesarean section could be due to incorporation of scalp $\mathrm{pH}$

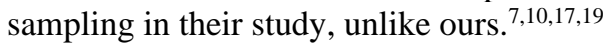

Fujikura et al, observed that the incidence of meconium staining was significantly more with increased birth weight more than $3 \mathrm{kgs} .{ }^{20}$ But in our study, there was no difference between MSG and control group in respect of birth weight. In both groups about same number of babies are of $>3 \mathrm{kgs}$ birth weight but mean birth weight was high in study group $2.92 \mathrm{~kg}$ where as in control group $2.88 \mathrm{kgs}$, which was compare with different studies. ${ }^{10,21}$ Approximately $27 \%$ cases of study group were unbooked in comparison to control (19\%). This study, in accordance with the study done by Bhide et al, showed that a majority of cases with MSAF were unbooked. ${ }^{22}$

The commonest associated abnormal fetal heart rate pattern observed in this study was bradycardia (36\%) in MSG whereas tachycardia was $13 \%$. Babies complicated by still birth and asphyxia in bradycardia group more $(29.54 \%)$ than the babies delivered having normal fetal heart rate pattern $(9.52 \%)$. Wong et al, and Naqvi have observed similar results. ${ }^{19,23}$ In our study non-reactive NST was two times more in study group compared to control group and was also more in thick group $51 \%$ compared to thin group $20 \%$, which was consistent with Rosario. ${ }^{14}$ Majority of the authors observed that incidence of birth asphyxia among the babies born with MSAF was more compared to the control cases with clear AF. Workers like Walker $\mathbf{J}$ and Desmond concluded that this high rate of depressed babies in stained group was the result of intrauterine hypoxia., ${ }^{9,24}$ In present series incidence of birth asphyxia in study group was nearly two times $(18.18 \%)$ as compared to control group (7.43\%) which was consistent with Meis and Khatun M. ${ }^{25}$

In control group $92.5 \%$ of cases had Apgar score of 7-10 at 1 minute and $7.44 \%$ cases had less than 7 , while in 
study group babies had Apgar score at 1 minute 7-10 in $81.66 \%$ and Apgar score was less than 7 in $18.33 \%$ babies. Only 5.2\% babies had Apgar score of less than 7 at 5 minutes in study group and only $2 \%$ babies had Apgar score less than 7 at 5 minutes in control group. Similar observation of Apgar score was recorded by Rosario. ${ }^{14}$ In control group $100 \%$ babies had Apgar score at 5 minutes $>7$. But in study group delivered by LSCS had Apgar score at 5 minutes $<7$ in about $4.77 \%$ and more than 7 in $95.23 \%$.

Neonatal morbidity was significantly associated with MSAF and it was $38 \%$ in study group, where as $16 \%$ in control group, morbidity was more in thick group 52\% than that of in thin group 20\%. Shaikh EM et al from Pakistan reported $46 \%$ morbidity. ${ }^{26}$ Admission to NICU was more in cases $(20 \%)$ than that of control group; it is due to associated meconium aspiration in study group babies. Wongs $\mathrm{F}$ et al and Patil et al found similar results in their study. ${ }^{17,19}$ In present study perinatal death was $4 \%$ in study group and $100 \%$ perinatal mortality was observed in thick meconium group that was not statistically significant $(\mathrm{P}>0.05)$. In the series of other authors perinatal mortality ranged from $2.5 \%$ to $7.1^{10,17,23}$ $7 \%$ and they had similar observation as compared to present study. First week neonatal death was $3.30 \%$, it is $100 \%$ due to MAS, which accounted for $40 \%$ of MAS babies. So, meconium was responsible for $100 \%$ neonatal death and it was common in MSG, difference was not statistically significant, $(\mathrm{P}>0.1)$. Arun observed $3.42 \%$ neonatal death. ${ }^{11}$

In our study mortality and morbidity in MSAF was comparable to other study as observed by Sharma U, where morbidity was $32.6 \%$ and mortality $6 \%$ in comparison with our study it was $27 \%$ and $4 \%$ respectively. ${ }^{27}$ The fetal outcome was adversely affected by the presence of meconium which was statistically significant in our study $(\mathrm{P}<0.01)$.

\section{CONCLUSION}

Meconium staining of amniotic fluid is a commonly observed phenomenon as well as common fetal hazard in obstetrics. As shown in the study thick meconium are associated with increased operative interventions, highest incidence of meconium staining during labour, low Apgar scores, increased risk of birth asphyxia, meconium aspiration syndrome, fetal heart rate abnormalities and NICU admissions. From the observations of present study, it is confirmed that meconium staining of amniotic fluid adversely influence the fetal outcome $(\mathrm{P}<0.01)$.

Most of the centers in our country lack facilities for electronic fetal heart rate monitoring and fetal scalp blood studies. Under such circumstances only clinical evaluation of cases with meconium stained $\mathrm{AF}$ in necessary. It is therefore necessary to re-examine the importance of clinical methods and apply them to judge the fetal hypoxia and prevent its long-term sequelae. The best course would be careful intrapartum fetal heart rate monitoring and other measures to prevent fetal asphyxia. Immediate airway management, need for suction and intubation should be guided by the state of the new-born, rather than the presence of meconium.

In recent years there is a dramatic fall in the rates of stillbirths and neonatal deaths due to improvement in antenatal, intra natal care of pregnant woman and improved NICU care.

\section{ACKNOWLEDGMENTS}

Authors would like to thank the department of obstetrics and gynaecology, surgery, other staff of operation theatre and administration of LTMMC and LTMGH, Sion, Mumbai, for permission to study and providing facility to carry out the work.

Funding: No funding sources

Conflict of interest: None declared

Ethical approval: The study was approved by the Institutional Ethics Committee

\section{REFERENCES}

1. Bacsik RD. Meconium aspiration syndrome. Pediatric Clin N Am. 1997;24(3):463-77.

2. Smith CA, Nelson NM. The physiology of the Newborn Infant, $4^{\text {th }}$ ed. Springfield, IL: Charles C Thomas; 1976:69-72.

3. Cunnigham FG. Intrapartum Assessment, William Obstetrics, 20 ${ }^{\text {th }}$ ed, Stamford, Connecticut: Appleton and Lange, A Simon and Schuster company; 1997:362-368.

4. Wiswell TE, Fuloria M. Management of meconium stained amniotic fluid. Clinics Perinatol. 1999;26(3):659-65.

5. Klinger MC, Kruse J. Meconium aspiration syndrome: pathophysiology and prevention. J Am Board Fam Med. 1999;12:6.

6. Ahanya SN, Lakshmanan J, Morgan BL, Ross MG. Meconium passage in utero: mechanisms, consequences, and management. Obstet Gynecol Survey. 2005;60(1):45-56.

7. Manning FA, Platt LD, Sipos L. Antepartum fetal evaluation: development of a fetal biophysical profile. Am J Obstet Gynecol. 1980;136(6):787-95.

8. Divon MY, Marks AD, Henderson CE. Longitudinal measurement of amniotic fluid index in postterm pregnancies and its association with fetal outcome. Am J Obstet Gynecol. 1995;172(1 Pt 1):142-6.

9. Rutherford SE, Phelan JP, Smith CV, Jacobs N. The four-quadrant assessment of amniotic fluid volume: an adjunct to antepartum fetal heart rate testing. Obstet Gynecol. 1987;70(3 Pt 1):353-6.

10. Goud PKU. Significance of meconium staining of anmiotic fluid in labour. J Obstet Gynaecol India. 1989;(39):523-6. 
11. Arun H, Nayek ARD. Meconium staining of amniotic fluid - significance and fetal outcome. J Obstet Gynaecol India. 1991;(41):480-3.

12. Bhaskar SH, Karthikeyan G, Bhat BV, Bhatia BD. Antenatal risk factors and neonatal outcome in meconium aspiration syndrome. Indian journal of maternal and child health. Official Pub Indian Mat Child Health Assoc. 1997;8(1):9-12.

13. Debdas AK. Meconium stained liquor - Reappraisal. J Obstet Gynaecol India. 1981;(31):924-9.

14. Rosario MC. Meconium staining of amniotic fluid in low risk parturients. J Obstet Gynaecol India. 1996;(46):642-6.

15. Blackwell SC, Wolfe HM, Redman ME, Hassan SS, Berry SM, Treadwell MC, et al. Relationship between meconium staining and amniotic fluid volume in term pregnancies. Fetal Diagnos Ther. 2002;17(2):78-82.

16. Kamala S, Amuchou SS, Sindhu S. Advances in the management of meconium aspiration syndrome. Int $\mathrm{J}$ Pediatr. 2011;2012.

17. Patil KP SM, Samatha KA. One-year cross sectional study of management practices of meconium stained amniotic fluid and perinatal outcome. J Obstet Gynecol India. 2006;56(2):128-30.

18. Naveen KS, Ritu S, Kushia P. Predictors of meconium stained amniotic fluid: a possible strategy to reduce neonatal morbidity and mortality. J Obstet Gynecol India. 2006;56(6):514-7.

19. Wong SF CK, Ho LC. The relative risk of fetal distress in pregnancy associated with meconiumstained liquor at different gestation. J Obstet Gynecol India. 2002;22(6):594-9.

20. Fujikura T, Klionsky B. The significance of meconium staining. Am J Obstet Gynecol. 1975;121(1):45-50.
21. Miller FC, Sacks DA, Yeh SY, Paul RH, Schifrin BS, Martin CB, et al. Significance of meconium during labor. Am J Obstet Gynecol. 1975;122(5):573-80.

22. Bhide SS, Shedurnikar N, Aiyer S, Baxi SR. Neonatal outcome after meconium stained amniotic fluid. J Obstet Gynecol India. 1993;44:933-5.

23. Naqvi SB. Association of meconium stained amniotic fluid with perinatal outcome in pregnant women of 37-weeks gestation. Pak J Surg. 2011;27(4):292-8.

24. Desmond MM, Moore J, Lindley JE. Meconium staining of the amniotic fluid - a marker of fetal hypoxia. Obstet Gynecol. 1957;9:91-103.

25. Khatun HA, Haque E, Kamal MA, Mamun MA, Khan MAH, Hoque MM. Fetal outcome in deliveries with meconium stained liquor. Bangladesh J Child Health. 2009;33(2):41-5.

26. Shaikh SM, Shaikh MA. Neonatal outcome in meconium stained amniotic fluid-on year experience. JPMA, 2010;(60):711.

27. Gokhroo SUK, Sharma M. Perinatal outcome in meconium stained amniotic fluid. Am J Obstet Gynecol Practice. 2004;8(4):37.

Cite this article as: Kapote DS, Mohite AM, Syed A. Comparative analysis of maternal and fetal outcome in meconium stained amniotic fluid and clear liquor in primigravida. Int J Reprod Contracept Obstet Gynecol 2020;9:482-7. 